TITLE:

\title{
Enzymatic characterization of human immunodeficiency virus type 1 reverse transcriptase for use in cDNA synthesis.
}

$\operatorname{AUTHOR}(\mathrm{S}):$

Konishi, Atsushi; Shinomura, Mayu; Yasukawa, Kiyoshi

\section{CITATION:}

Konishi, Atsushi ...[et al]. Enzymatic characterization of human immunodeficiency virus type 1 reverse transcriptase for use in cDNA synthesis.. Applied biochemistry and biotechnology 2013, 169(1): 77-87

ISSUE DATE:

2013-01

URL:

http://hdl.handle.net/2433/169949

\section{RIGHT:}

The final publication is available at www.springerlink.com; この論文は 出版社版でありません。引用の際には出版社版をご確認ご利用くださ $\iota_{\circ}$; This is not the published version. Please cite only the published version. 
Enzymatic Characterization of Human Immunodeficiency Virus Type 1 Reverse Transcriptase for Use in cDNA Synthesis

\section{Atsushi Konishi • Mayu Shinomura $\cdot$ Kiyoshi Yasukawa}

Division of Food Science and Biotechnology, Graduate School of Agriculture, Kyoto University, Sakyo-ku, Kyoto 606-8502, Japan

DMSO, dimethyl sulfoxide; HIV-1, human immunodeficiency virus type 1; HIV-1 M, HIV-1 group M; HIV-1 O, HIV-1 group O; MMLV, Moloney murine leukemia virus; PMSF, phenylmethylsulfonyl fluoride; RT, reverse transcriptase; T/P, template-primer; TCA, trichloroacetic acid.

*Correspondence author. Tel.:+81 75753 6267; fax: +81 757536265 .

E-mail: yasukawa@kais.kyoto-u.ac.jp (K. Yasukawa). 


\begin{abstract}
The aim of this study is to explore the advantages of using human immunodeficiency virus type 1 (HIV-1) reverse transcriptase (RT) in cDNA synthesis. Recombinant HIV-1 group M (HIV-1 M) RT and HIV-1 group O (HIV-1 O) RT were produced in an Escherichia coli expression system. In the incorporation of dTTP into poly(rA)-p(dT) $)_{15}(\mathrm{~T} / \mathrm{P})$, the $K_{\mathrm{m}}$ values for dTTP of HIV-1 M RT and HIV-1 O RT were 8 and $12 \%$ of that of Moloney murine leukemia virus (MMLV) RT, respectively, and the $K_{\mathrm{m}}$ values for T/P were 25 and $23 \%$ of that of MMLV RT, respectively. Compared with MMLV RT, HIV-1 M RT and HIV-1 O RT were less susceptible to formamide, which is frequently used for cDNA synthesis with a G+C-rich RNA to improve specificity. The high substrate affinity and low susceptibility to formamide of HIV-1 RT might be advantageous for its use in cDNA synthesis.
\end{abstract}

Keywords cDNA - formamide $\cdot \mathrm{HIV}-1 \cdot \mathrm{MMLV} \cdot$ reverse transcriptase 


\section{Introduction}

Reverse transcriptase (RT) is the enzyme responsible for viral genome replication. Moloney murine leukemia virus (MMLV) RT and Avian myeloblastosis virus (AMV) RT are widely used in cDNA synthesis. MMLV RT is a $75-\mathrm{kDa}$ monomer comprising the fingers, palm, thumb, and connection subdomains and the RNase $\mathrm{H}$ domain [1-3]. AMV RT is a heterodimer consisting of a $63-\mathrm{kDa} \alpha$ subunit and a $95-\mathrm{kDa} \beta$ subunit. Human immunodeficiency virus type 1 (HIV-1) RT is widely used as a tool in the development of inhibitors for the treatment of HIV-1 infection. It is a heterodimer consisting of a 51-kDa subunit (p51) and 66-kDa subunit (p66). p66 comprises the same five domains as MMLV RT, and p51 comprises the fingers, palm, thumb, and connection subdomains but lacks the RNase H domain [4-6]. HIV-1 RT exists as a heterodimer as well as a homodimer, and the dissociation constants $\left(K_{\mathrm{d}}\right)$ of p51 and p66, p66 and p66, and p51 and p51 were reported to be $0.31,4.2$, and $230 \mu \mathrm{M}$, respectively [7]. HIV-1 is classified into four phylogenetic major groups: $\mathrm{M}$ (main), $\mathrm{O}$ (outlier), $\mathrm{N}$ (non-M/non-O), and P. Group $\mathrm{M}$ infection is spread all over the world. Group $\mathrm{O}$ infection is restricted to Cameroon and neighboring countries in West Central Africa [8]. The amino acid sequence homology between HIV-1 group M (HIV-1 M) RT and HIV-1 group O (HIV-1 O) RT is $79 \%$ [8].

It is well known that the fidelity of HIV-1 RT is lower than those of MMLV RT and AMV RT [9]. Concerning this, Barrioluengo et al. reported that two single mutations $($ Lys65 $\rightarrow$ Arg and Arg78 $\rightarrow$ Ala) and one double mutation $($ Lys65 $\rightarrow$ Arg/Val75 $\rightarrow$ Ile) increase the fidelity of HIV-1 O RT to the same level as MMLV RT [9]. In addition, Álvarez et al. reported that HIV-1 O RT is more thermostable than MMLV RT [10]. 
These results indicate that the HIV-1 O RT variants K65R, R78A, and K65R/V75I have the same fidelity as, and higher stability than MMLV RT.

Low fidelity of RT is problematic for cloning of cDNA. However, extremely high fidelity is not required for detection of a target RNA in RT-PCR and RNA-specific amplification assays. RNA-specific amplification is an isothermal reaction $\left(41-43{ }^{\circ} \mathrm{C}\right)$ that is widely used in clinical diagnosis [11-14], in which RT synthesizes promoter-bearing double-stranded DNA with the help of its RNase H activity, and RNA polymerase continues in vitro transcription to produce copies of RNA fragments that are subsequently recycled as RNA templates for synthesis of promoter-bearing double-stranded DNA. To increase the sensitivity and rapidness, the reaction is carried out in the presence of deoxy-inosine triphosphate (dITP) and dimethyl sulfoxide (DMSO). The use of dITP surely decreases the fidelity of RT.

In this study, we made enzymatic characterization of HIV-1 RT. The results have shown that HIV-1 RT has high substrate affinity and low susceptibility to formamide. These characteristics might be advantageous for using HIV-1 RT in cDNA synthesis.

\section{Materials and methods}

Materials

$\mathrm{p}(\mathrm{dT})_{15}$ was purchased from Life Technologies Japan Ltd. (Tokyo, Japan). [methyl- $\left.{ }^{3} \mathrm{H}\right] \mathrm{dTTP}(1.52 \mathrm{TBq} / \mathrm{mmol})$ and poly(rA) were from GE Healthcare (Buckinghamshire, UK). The RT concentration was determined by the method of 
Bradford [15] using Protein Assay CBB Solution (Nacalai Tesque, Kyoto, Japan) with bovine serum albumin (Nacalai Tesque) as standard. Standard RNA, an RNA of 1014-nucleotides corresponding to DNA sequence 8353-9366 of the cesA gene of Bacillus cereus (GenBank accession no. DQ360825), was prepared by an in vitro transcription [14].

Plasmids

The 2,002-bp DNA fragment encoding MMLV RT was amplified from the pUC19 plasmid that contains the complete MMLV gene (8,332 bp) (GenBank accession no. J02255) [14], using the primers MRF and MRHISB. The 1,340-bp DNA fragment encoding HIV-1 M RT p51 gene was amplified using HIVRTM-HISF and HIVRTMp51-B, and the 1,706-bp DNA fragment encoding HIV-1 M RT p66 was amplified using HIVRTM-F and HIVRTMp66-B, both from the artificially synthesized HIV-1 M RT gene (Fig. S1A). The 1,340-bp DNA fragment encoding HIV-1 O RT p51 gene was amplified using HIVRTO-HISF and HIVRTOp51-B, and the 1,706-bp DNA fragment encoding HIV-1 O RT p66 was amplified using HIVRTO-F and HIVRTOp66-B, both from the artificially synthesized HIV-1 O RT gene (Fig. S1B). The nucleotide sequences of the primers are shown in Table S1. These amplified DNAs were digested with $N d e \mathrm{I}$ and EcoRI, and inserted in pET-22b(+) to produce pET-MRTHis, pET-HisHIVMp51, pET-HIVMp66, pET-HisHIVOp51, and pET-HIVOp66 (Fig. 1).

Expression and Purification of MMLV RT 
BL21(DE3) [F-, ompT, $h s d S_{B}\left(r_{B}-m_{B}-\right)$ gal dcm (DE3)] cells were transformed with pET-HisMRT. The overnight culture of the transformants $(8 \mathrm{~mL})$ was added to $800 \mathrm{~mL}$ of $\mathrm{L}$ broth and incubated with shaking at $37^{\circ} \mathrm{C}$. When $O D_{660}$ reached $0.6-0.8,0.8 \mathrm{~mL}$ of 0.5 M IPTG was added and growth was continued at $30^{\circ} \mathrm{C}$ for $4 \mathrm{~h}$. After centrifugation at $10,000 \times g$ for $10 \mathrm{~min}$, the cells were harvested, suspended with $20 \mathrm{~mL}$ of $10 \mathrm{mM}$ Tris- $\mathrm{HCl}, 0.4 \% \mathrm{v} / \mathrm{v}$ Triton $\mathrm{X}-100,10 \% \mathrm{v} / \mathrm{v}$ glycerol, $1 \mathrm{mM}$ phenylmethylsulfonyl fluoride (PMSF), $\mathrm{pH} 7.5$ and disrupted by sonication. After centrifugation at 15,000 $\times g$ for $20 \mathrm{~min}$, the supernatant was collected, to which solid $\left(\mathrm{NH}_{4}\right)_{2} \mathrm{SO}_{4}$ was added to a final concentration of $40 \%$ saturation. After centrifugation at $20,000 \times g$ for $20 \mathrm{~min}$, the pellet was collected and dissolved in $6 \mathrm{~mL}$ of $0.02 \mathrm{M}$ potassium phosphate, $2.0 \mathrm{mM}$ dithiothreitol (DTT), $10 \%$ glycerol, pH 7.2 (0.02 M PDG) and dialyzed against the same buffer. The dialyzed solution was diluted to $60 \mathrm{~mL}$ with $2.0 \mathrm{mM}$ DTT, $10 \%$ glycerol, $\mathrm{pH}$ $7.2(\mathrm{DG})$ and applied to a column [25 mm (inner diameter) $\times 120 \mathrm{~mm}]$ packed with Toyopearl DEAE-650M gel (Tosoh, Tokyo, Japan) equilibrated with 0.02 M PDG. The bound RT was eluted with $0.3 \mathrm{M}$ potassium phosphate, $2.0 \mathrm{mM}$ DTT, $10 \%$ glycerol, $\mathrm{pH}$ 7.2 (0.3 M PDG). The eluate $(10-15 \mathrm{~mL})$ was diluted to $100 \mathrm{~mL}$ with $0.02 \mathrm{M}$ PDG containing $20 \mathrm{mM}$ imidazole and applied to the column packed with a $\mathrm{Ni}^{2+}$-sepharose (HisTrap HP $1 \mathrm{~mL}$, GE Healthcare, Buckinghamshire, UK) equilibrated with $0.02 \mathrm{M}$ PDG containing $20 \mathrm{mM}$ imidazole. The bound RT was eluted with $0.02 \mathrm{M}$ PDG containing $500 \mathrm{mM}$ imidazole. The eluate was dialyzed against $20 \mathrm{mM}$ potassium phosphate, $2.0 \mathrm{mM}$ DTT, $50 \%$ glycerol, $\mathrm{pH} 7.2$, and stored at $-80^{\circ} \mathrm{C}$.

Expression and Purification of HIV-1 M RT and HIV-1 O RT 
BL21(DE3) cells were transformed with pET-HisHIVMp51, pET-HIVMp66, pET-HisHIVOp51, or pET-HIVOp66, cultured, harvested, and suspended by the same method used for MMLV RT. For the production of HIV-1 M RT, the suspension

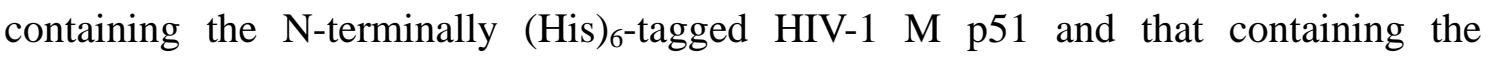
untagged HIV-1 M p66 were mixed. For the production of HIV-1 O RT, the suspension containing the N-terminally (His) 6-tagged HIV-1 O p51 and that containing the untagged HIV-1 O p66 were mixed. HIV-1 M RT and HIV-1 O RT were purified and stored by the same methods used for MMLV RT.

Measurement of RT activity to Incorporate dTTP into poly(rA)-p(dT) 15

The activity to incorporate dTTP into poly $(\mathrm{rA})-\mathrm{p}(\mathrm{dT})_{15}$ was measured as described previously [16]. Briefly, the reaction was carried out in $25 \mathrm{mM}$ Tris- $\mathrm{HCl}(\mathrm{pH} \mathrm{8.3),} 50$ $\mathrm{mM} \mathrm{KCl}, 2.0 \mathrm{mM}$ DTT, $5.0 \mathrm{mM} \mathrm{MgCl}_{2}, 25 \mu \mathrm{M}$ poly(rA)-p(dT) ${ }_{15}$ (this concentration expressed as that of $\left.\mathrm{p}(\mathrm{dT})_{15}\right), 0.2 \mathrm{mM}\left[{ }^{3} \mathrm{H}\right] \mathrm{dTTP}$, and active fractions or purified preparations of $\mathrm{RT}$ at $37^{\circ} \mathrm{C}$. An aliquot $(20 \mu \mathrm{L})$ was taken from the reaction mixture at a predetermined time and immediately spotted onto the glass filter GF/C $2.5 \mathrm{~cm}$ (Whatman, Middlesex, UK). The amounts of $\left[{ }^{3} \mathrm{H}\right] \mathrm{dTTP}$ incorporated was counted, and the initial reaction rate was determined.

Measurement of RT Activity for cDNA Synthesis

The activity for cDNA synthesis was measured as described previously [14]. Briefly, the reaction $(20 \mu \mathrm{L})$ was carried out in $25 \mathrm{mM}$ Tris- $\mathrm{HCl}(\mathrm{pH} 8.3), 50 \mathrm{mM} \mathrm{KCl}, 2.0 \mathrm{mM}$ 
DTT, $0.1 \mathrm{mM}$ dNTP, $0.5 \mu \mathrm{M}$ DNA primer (R12), $0.8 \mathrm{pg} / \mu \mathrm{L}$ (corresponding to $2 \mathrm{pM}$ ) standard RNA, $0.05 \mu \mathrm{g} / \mu \mathrm{L}$ E. coli RNA, and various concentrations $(0.1-1000 \mathrm{nM})$ of $\mathrm{RT}$ at $46^{\circ} \mathrm{C}$ for $30 \mathrm{~min}$ and stopped by heating at $95^{\circ} \mathrm{C}$ for $5 \mathrm{~min}$. The PCR reaction $(30$ $\mu \mathrm{L}$ ) was then carried out in $50 \mathrm{mM} \mathrm{KCl}, 10 \mathrm{mM}$ Tris- $\mathrm{HCl}(\mathrm{pH} 8.3), 1.5 \mathrm{mM} \mathrm{MgCl} 2,0.5$ $\mu \mathrm{M}$ (each) DNA primers (F5 and RV), $0.1 \mathrm{mM}$ dNTP, $10 \% \mathrm{v} / \mathrm{v}$ product of the reverse transcriptase reaction, and $0.05 \mathrm{U} / \mu 1 \mathrm{Taq}$ polymerase. The cycling parameters were $95^{\circ} \mathrm{C}$ for $30 \mathrm{~s}$, followed by 30 cycles at $95^{\circ} \mathrm{C}$ for $30 \mathrm{~s}, 55^{\circ} \mathrm{C}$ for $30 \mathrm{~s}$, and $72^{\circ} \mathrm{C}$ for $60 \mathrm{~s}$. The amplified products were separated on $1.0 \%$ agarose gels and stained with ethidium bromide $(1 \mu \mathrm{g} / \mathrm{mL})$.

Analysis of Irreversible Thermal Inactivation of RT

Irreversible thermal inactivation of RT was analyzed as described previously [16]. Briefly, the thermal inactivation was carried out in $10 \mathrm{mM}$ potassium phosphate $(\mathrm{pH}$ 7.6), $2.0 \mathrm{mM}$ DTT, $0.2 \%$ v/v Triton X-100, $10 \%$ glycerol, $28 \mu \mathrm{M}$ poly(rA)-p(dT) 15 and $20 \mathrm{nM}$ MMLV RT, $500 \mathrm{nM}$ HIV-1 M RT, or $200 \mathrm{nM}$ HIV-1 O RT at a range of temperatures from 42 to $50^{\circ} \mathrm{C}$ for $10 \mathrm{~min}$ followed by incubation on ice for 30-60 min. The remaining RT activity to incorporate dTTP into poly(rA)-p(dT) ${ }_{15}$ was determined at $37^{\circ} \mathrm{C}$ as described above.

\section{Results}


Production of Recombinant MMLV RT, HIV-1 M RT, and HIV-1 O RT

To achieve a high-level production, we selected the C-terminus for MMLV RT and the $\mathrm{N}$-terminus for HIV-1 M RT and HIV-1 O RT as the (His) $)_{6}$ binding site and $30^{\circ} \mathrm{C}$ for all RTs as the E. coli culture temperature after IPTG induction. Figure 1 shows five

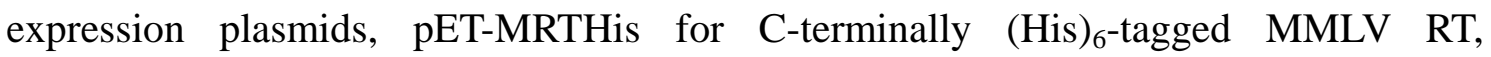
pET-HIVMp66 for untagged HIV-1 M p66, pET-HisHIVMp51 for N-terminally

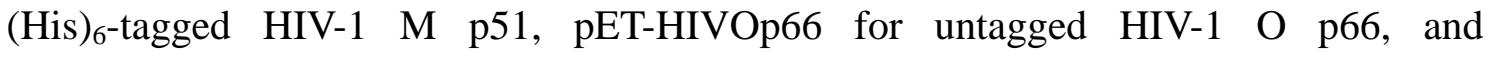
pET-HisHIVOp51 for N-terminally (His) ${ }_{6}$-tagged HIV-1 O p51.

Purification of MMLV RT was carried out from the E. coli cells containing the C-terminally (His)6-tagged MMLV RT. Purification of HIV-1 M RT and HIV-1 O RT was carried out from the mixture of the cells containing the untagged p66 and those containing the $\mathrm{N}$-terminally (His) ${ }_{6}$-tagged p51. Ammonium sulfate fractionation was used as the first step, ion-exchange column chromatography as the second step, and $\mathrm{Ni}^{2+}$ affinity column chromatography as the third step. The active fraction at the third step was dialyzed against the solution containing 50\% glycerol. Figure 2 shows the results of SDS-PAGE analysis of the active fractions at each purification stage and the purified enzyme preparations. MMLV RT yielded a single band with a molecular mass of 75 kDa, and HIV-1 M RT and HIV-1 O RT yielded two bands with molecular masses of 51 and $66 \mathrm{kDa}$. Representative purification is shown in Table S2.

Activities of Recombinant MMLV RT, HIV-1 M RT, and HIV-1 O RT

Figure 3 shows the results of steady-state kinetic analysis of RT in the incorporation of 
dTTP into poly $(\mathrm{rA})-\mathrm{p}(\mathrm{dT})_{15}(\mathrm{~T} / \mathrm{P})$. The dependences of the initial reaction rate $\left(v_{\mathrm{o}}\right)$ on dTTP (Fig. 3A) and T/P (Fig. 3B) concentrations exhibited the Michaelis-Menten curves. The $K_{\mathrm{m}, \mathrm{dTTP}}, K_{\mathrm{m}, \mathrm{T} / \mathrm{P}}$, and $k_{\text {cat }}$ values are summarized in Table 1 . The $K_{\mathrm{m}, \mathrm{dTTP}}$ and $K_{\mathrm{m}, \mathrm{T} / \mathrm{P}}$ values of the HIV-1 M RT and HIV-1 O RT were in the range of $8-25 \%$ of those of MMLV RT, suggesting that HIV-1 RT has higher affinity for dTTP and T/P than MMLV RT. The $k_{\text {cat }}$ values of HIV-1 M RT and HIV-1 O RT were 1.2 and $3.8 \%$ of that of MMLV RT, respectively. Consequently, the $k_{\text {cat }} / K_{\mathrm{m}}$ values of HIV-1 M RT and HIV-1 O RT were in the range of 5-32\% of those of MMLV RT.

Figure 4 shows cDNA synthesis activities of RT. The reaction was carried out at $46^{\circ} \mathrm{C}$ for 30 min with varying enzyme concentrations of $0-1,000 \mathrm{nM}$, followed by PCR of the cDNA synthesis reaction products and agarose gel electrophoresis of the PCR products. In all RTs, the amplified product with the expected size of $601 \mathrm{bp}$ was detected for the enzyme concentrations of $0.1-10 \mathrm{nM}$, but not for those of 50-1,000 nM. This indicates that all RTs have similar cDNA synthesis activities.

Formamide and dimethyl sulfoxide (DMSO) are frequently used for the polymerase chain reaction (PCR) with a G+C-rich DNA to improve specificity [18-20]. Figure 5 shows the activities of RT to incorporate dTTP into T/P in the presence of various concentrations $(0-30 \% \mathrm{v} / \mathrm{v})$ of formamide or DMSO at $42^{\circ} \mathrm{C}$. The relative activity was defined as the ratio of the initial reaction rate in the presence of the indicated organic solvent to that in its absence $\left(61.8 \mathrm{nM} \mathrm{s}^{-1}\right.$ for MMLV RT, $34.0 \mathrm{nM} \mathrm{s}^{-1}$ for HIV-1 M RT, and $33.9 \mathrm{nM} \mathrm{s}^{-1}$ for HIV-1 O RT). Formamide and DMSO inhibited the activity in a dose-dependent manner. The HIV-1 M RT and HIV-1 O RT activities were slightly enhanced in the presence of $4-18 \%$ formamide, and the MMLV RT activity was slightly enhanced in the presence of 2-16\% DMSO. The concentrations required to decrease the 
activities of MMLV RT, HIV-1 M RT, and HIV-1 O RT to 50\% of the maximum activity $\left(\mathrm{IC}_{50}\right)$ of formamide were 8,22 , and $22 \%$, respectively, and those of DMSO were 21,16 , and $16 \%$, respectively. This indicates that Formamide affects MMLV RT more potently than HIV-1 M RT and HIV-1 O RT, while DMSO affects HIV-1 M RT and HIV-1 O RT more potently than MMLV RT.

Stabilities of Recombinant MMLV RT, HIV-1 M RT, and HIV-1 O RT

Figure 6 shows the remaining activities of RT to incorporate dTTP into T/P after thermal treatment at $42-50^{\circ} \mathrm{C}$ for $10 \mathrm{~min}$. The relative activities, which were defined as the ratio of the initial reaction rate with incubation at the indicated temperature for 10 min to that without incubation, of all RTs decreased with increasing temperature. The relative activities of HIV-1 O RT were higher than those of MMLV RT and HIV-1 M RT at all temperatures examined. The temperatures reducing initial activity by $50 \%$ in 10-min incubation, $T_{50}$, of MMLV RT, HIV-1 M RT, and HIV-1 O RT were estimated about 44,42 , and $46^{\circ} \mathrm{C}$. This suggests that the thermal stability of HIV-1 O RT is slightly higher than those of MMLV RT and HIV-1 M RT.

\section{Discussion}

In the dTTP incorporation reaction, the $K_{\mathrm{m}}$ and $k_{\text {cat }}$ values of HIV-1 M RT and HIV-1 O RT were lower than those of MMLV RT (Fig. 3, Table 1). This finding suggests that HIV-1 RT has higher substrate affinity but lower enzyme processivity than 
MMLV RT. All three RTs exhibited similar cDNA synthesis activities (Fig. 4). In the dTTP incorporation reaction, the initial substrate concentrations $(0.2 \mathrm{mM}$ dTTP and 25 $\mu \mathrm{M}$ T/P) were higher than the enzyme concentration $(2-20 \mathrm{nM})$, whereas in the cDNA synthesis reaction, the initial substrate concentration (2 pM target RNA) was lower than the enzyme concentration $(0.1-10 \mathrm{nM})$. In most cDNA synthesis reactions, the initial concentration of target RNA is considerably lower than that of the RT. Thus, HIV-1 RT has an advantage over MMLV RT because it has a higher substrate affinity. HIV-1 can infect both dividing and non-dividing cells, whereas, MMLV can infect only dividing cells. The clear difference in kinetic parameters can be explained by the fact that RT has evolved to facilitate viral replication under specific cellular environments with different substrate concentrations. Such differences for recombinant RTs were reported in feline leukemia virus and feline immunodeficiency virus [21].

All RTs exhibited similar cDNA synthesis defects at high enzyme concentrations (50-1,000 nM). Similar result was obtained for the MMLV RT variant D524A, wherein the catalytically important residue for RNase H activity, Asp524, was substituted with Ala to abolish RNase $\mathrm{H}$ activity and increase stability (data not shown). We speculate that this defect is due to increased nonspecific binding of RT to T/P rather than enhanced RNA cleavage.

We previously reported that $6-8 \%$ formamide and $12 \%$ DMSO improved the efficiency of MMLV RT-catalyzed cDNA synthesis at low temperatures $\left(25-34^{\circ} \mathrm{C}\right)[20]$. We presume this effect is due to the increase in primer specificity caused by reducing secondary RNA structure and nonspecific binding of the primer, as previously reported $[18,19]$. Formamide is also used in RNA isolation [22] and storage [23]. In this study, compared with MMLV RT, HIV-1 M RT and HIV-1 O RT were less susceptible to 
formamide but more susceptible to DMSO (Fig. 5), suggesting that formamide more effectively enhances cDNA synthesis by HIV-1 RT. The mechanism underlying the difference in the inhibitory effects of DMSO and formamide on MMLV RT and HIV-1 RT activity is unknown.

HIV-1 O RT exhibited slightly higher thermal stability than MMLV RT and HIV-1 M RT (Fig. 6), which is in agreement with the previous report [10]. The reason for the difference in stability of HIV-1 M RT and HIV-1 O RT is unknown. We generated a highly thermostable MMLV RT variant, E286R/E302K/L435R/D524A, by introducing positive charges into the positions that have been implicated in the interaction with T/P by site-directed mutagenesis [24]. We also generated a highly stable AMV RT $\alpha$ subunit variant V238R/L388R/D450A by introducing the triple mutation $(\mathrm{Val238} \rightarrow \mathrm{Arg} / \mathrm{Leu} 388 \rightarrow \mathrm{Arg} / \mathrm{Asp} 450 \rightarrow \mathrm{Ala})$ corresponding to the mutation introduced into MMLV RT (Glu286 $\rightarrow$ Arg/Leu435 $\rightarrow$ Arg/Asp524 $\rightarrow$ Ala) [25]. Same strategy might be applicable to stabilize HIV-1 M RT and HIV-1 O RT.

In conclusion, both HIV-1 M RT and HIV-1 O RT exhibited high affinity for DNA-primed RNA template and low susceptibility to formamide. Our results suggest that the use of HIV-1 RT in cDNA synthesis is attractive for detection of a small number of target RNA molecules.

\section{Acknowledgments}

This study was supported in part (K.Y.) by Grants-in-Aid for Scientific Research (nos. 19580104 and 21580110) from the Japan Society for the Promotion of Science and Daiwa Securities Health Foundation. 


\section{References}

1 Kimmel, A. R., \& Berger, S. L. (1987) Methods in Enzymology, 152, 307-316.

2 Georgiadis, M. M., Jessen, S. M., Ogata, C. M., Telesnitsky, A., Goff, S. P., \& Hendrickson, W. A. (1995) Structure, 3, 879-892.

3 Lim, D., Gregorio, G. G., Bingman, C., Martinez-Hackert, E., Hendrickson, W. A., \& Goff, S. P. (2006) Journal of Virology, 80, 8379-8389.

4 di Marzo Veronese, F., Copeland, T. D., DeVico, A. L., Rahman, R., Oroszlan, S., Gallo, R. C., \& Sarngadharan, M. G. (1986) Science, 231, 1289-1291.

5 Patel, P. H., Jacobo-Molina, A., Ding, J., Tantillo, C., Clark, A. D. Jr., Raag, R., Nanni, R. G., Hughes, S. H., \& Arnold, E. (1995) Biochemistry, 34, 5351-5363.

6 Ding, J., Das, K., Hsiou, Y., Sarafianos, S. G., Clark, A. D. Jr., Jacobo-Molina, A., Tantillo, C., Hughes, S. H., \& Arnold, E. (1998) Journal of Molecular Biology, 284, 1095-1111.

7 Venezia, C. F., Meany, B. J., Braz, V. A., \& Barkley, M. D. (2006) Biochemistry, 48, 9084-9093.

8 Buonaguro, L., Tornesello, M. L., \& Buonaguro, F. M. (2007) Journal of Virology, $81,10209-10219$.

9 Barrioluengo, V., Álvarez, M., Barbieri, D., \& Menéndez-Arias, L. (2011) Biochemical Journal, 436, 599-607.

10 Álvarez, M., Matamoros, T., \& Menéndez-Arias, L. (2009) Journal of Molecular Biology, 392, 872-884.

11 Kievits, T., van Gemen, B., van Strijp, D., Schukkink, R., Dircks, M., Adriaanse, 
H., Malek, L., Sooknanan, R., \& Lens, P. (1991) Journal of Virological Methods, $35,273-286$.

12 Ishiguro, T., Saitoh, J., Horie, R., Hayashi, T., Ishizuka, T., Tsuchiya, S., Yasukawa, K., Kido, T., Nakaguchi, Y., Nishibuchi, M. \& Ueda, K. (2003) Analytical Biochemistry, 314, 77-86.

13 Masuda, T., Yasukawa, K., Isawa, Y., Horie, R., Saitoh, J., Ishiguro, T., Nakaguchi, Y., Nishibuchi, M., \& Hayashi, T. (2004) Journal of Bioscience and Bioengineering, 98, 236-243.

14 Yasukawa, K., Agata, N., \& Inouye, K. (2010) Enzyme Microbial Technology, 46, $391-396$.

15 Bradford, M. M. (1976) Analytical Biochemistry, 72, 248-254.

16 Yasukawa, K., Nemoto, D., \& Inouye, K. (2008) Journal of Biochemistry, 143, $261-268$

17 Konishi, A., Nemoto, D., Yasukawa, K., \& Inouye, K. (2011) Bioscience, Biotechnology, and Biochemistry 75, 1618-1620.

18 Chester, N., \& Marshak, D. R. (1993) Analytical Biochemistry, 209, 284-290.

19 Sarkar, G., Kapelner, S., \& Sommer, S. S. (1990) Nucleic Acids Research, 18, 7465

20 Yasukawa, K., Konishi, A., \& Inouye, K. (2010) Bioscience, Biotechnology, and Biochemistry, 74, 1925-1930.

21 Operario, D. J., Reynolds, H. M., \& Kim, B. (2005) Virology, 335, 106-121.

22 Bowrin, V., Rouse-Miller, J., Sutton, F., \& Sirju-Charran, G. (2012) Phytochemical Analysis, doi 10.1002/pca.2390.

23 Swinson, K., \& Koban, M. (2005) Journal of Biochemical and Biophysical 
Methods, 63, 149-153.

24 Yasukawa, K., Mizuno, M., Konishi, A., \& Inouye, K. (2010) Journal of Biotechnology, 150, 299-306.

25 Konishi, A., Yasukawa, K., \& Inouye, K. (2012) Biotechnology Letters, 34, $1209-1215$. 


\section{Figure legends}

Fig. 1 Expression plasmids. The structures of pET-MRTHis, pET-HIVMp66, pET-HisHIVMp51, pET-HIVOp66, and pET-HisHIVOp51 are shown. The asterisk indicates the termination codon

Fig. 2 SDS-PAGE analysis. CBB-stained 10\% SDS-polyacryl amide gel is shown. (A-C) Active fractions of each purification stage for MMLV RT (A), HIV-1 M RT (B), and HIV-1 O RT (C). Lanes: marker proteins (lane 1), soluble fractions of the total extracts (lane 2), the centrifuged pellets after fractionation by ammonium sulfate at $40 \%$ saturation (lane 3), active fractions of ion-exchange chromatography (lane 4) and $\mathrm{Ni}^{2+}$ affinity chromatography before (lane 5) and after (lane 6) dialysis

Fig. 3 Dependence on substrate concentration of the initial reaction rate $\left(v_{\mathrm{o}}\right)$ in the incorporation of dTTP into poly(rA)-p(dT) ${ }_{15}$. (A) Dependence on dTTP concentration. (B) Dependence on poly $(\mathrm{rA})-\mathrm{p}(\mathrm{dT})_{15}$ concentration. The initial concentrations of MMLV RT, HIV-1 M RT, and HIV-1 O RT were 2, 50, and $20 \mathrm{nM}$, respectively. The initial concentration of poly(rA)-p(dT) $)_{15}$ was $25 \mu \mathrm{M}(\mathrm{A})$, and that of dTTP was $200 \mu \mathrm{M}$ (B). Solid lines represent the best fit of the Michaelis-Menten equation with the non-linear least squares method. Symbols for the enzymes: MMLV RT (open circle), HIV-1 M RT (open triangle), and HIV-1 O RT (open square)

Fig. 4 Dependence on enzyme concentration of RT-catalyzed cDNA synthesis. (A) MMLV RT. (B) HIV-1 M RT. (C) HIV-1 O RT. cDNA synthesis was carried out with 0 
(lane 2), 0.1 (lane 3), 0.5 (lane 4), 1.0 (lane 5), 5.0 (lane 6), 10 (lane 7), 50 (lane 8), 100 (lane 9), 500 (lane 10), 1,000 (lane 11) nM MMLV RT (A), HIV-1 M RT (B), and HIV-1 O RT (C) at $46^{\circ} \mathrm{C}$. Then, PCR was carried out. Marker DNAs (lane 1) and the amplified products (lanes 2-11) were separated on $1.0 \%$ agarose gels and stained with ethidium bromide. The arrow indicates the expected size $(601 \mathrm{bp})$ of the amplified products

Fig. 5 Dependence on organic solvent concentration of RT-catalyzed incorporation of dTTP into poly(rA)-p(dT) 15 . The reaction was carried out at $42^{\circ} \mathrm{C}$ with the initial enzyme concentrations of $2 \mathrm{nM}$ for MMLV RT, $50 \mathrm{nM}$ for HIV-1 M RT, and $20 \mathrm{nM}$ for HIV-1 O RT and the initial poly(rA)-p(dT) 15 and $\left[{ }^{3} \mathrm{H}\right] \mathrm{dTTP}$ concentrations of $25 \mu \mathrm{M}$ and $0.2 \mathrm{mM}$, respectively, in the presence of $0-30 \%$ formamide (A) or DMSO (B). Symbols for the enzymes: MMLV RT (open circle), HIV-1 M RT (open triangle), and HIV-1 O RT (open square)

Fig. 6 Irreversible thermal inactivation of RT. MMLV RT (20 nM), HIV-1 M RT (500 $\mathrm{nM})$, and HIV-1 O RT (200 nM) were incubated at $42-50^{\circ} \mathrm{C}$ in the presence or absence of poly(rA)-p(dT) $)_{15}(\mathrm{~T} / \mathrm{P})(28 \mu \mathrm{M})$ for $10 \mathrm{~min}$. Then, the reaction to incorporate dTTP into poly(rA)-p(dT) 15 was carried out at $37^{\circ} \mathrm{C}$ with the initial enzyme concentrations of $2 \mathrm{nM}$ for MMLV RT, $50 \mathrm{nM}$ for HIV-1 M RT, and $20 \mathrm{nM}$ for HIV-1 O RT 


\begin{tabular}{|lr|}
\hline pET-MRTHis & $(7,818 \mathrm{bp})$ \\
pET-HIVMp66 & $(7,537 \mathrm{bp})$ \\
pET-HisHIVMp51 & $(7,153 \mathrm{bp})$ \\
pET-HIVOp66 & $(7,537 \mathrm{bp})$ \\
pET-HisHIVOp51 & $(7,153 \mathrm{bp})$ \\
\hline
\end{tabular}

pET-MRTHis

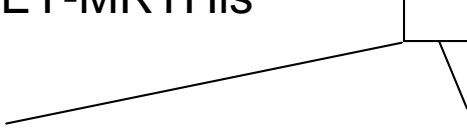

ATGACATGGCTGTCTGATTTTCCTCAG

$M \quad T \quad W \quad L \quad S \quad D \quad F \quad P \quad Q$

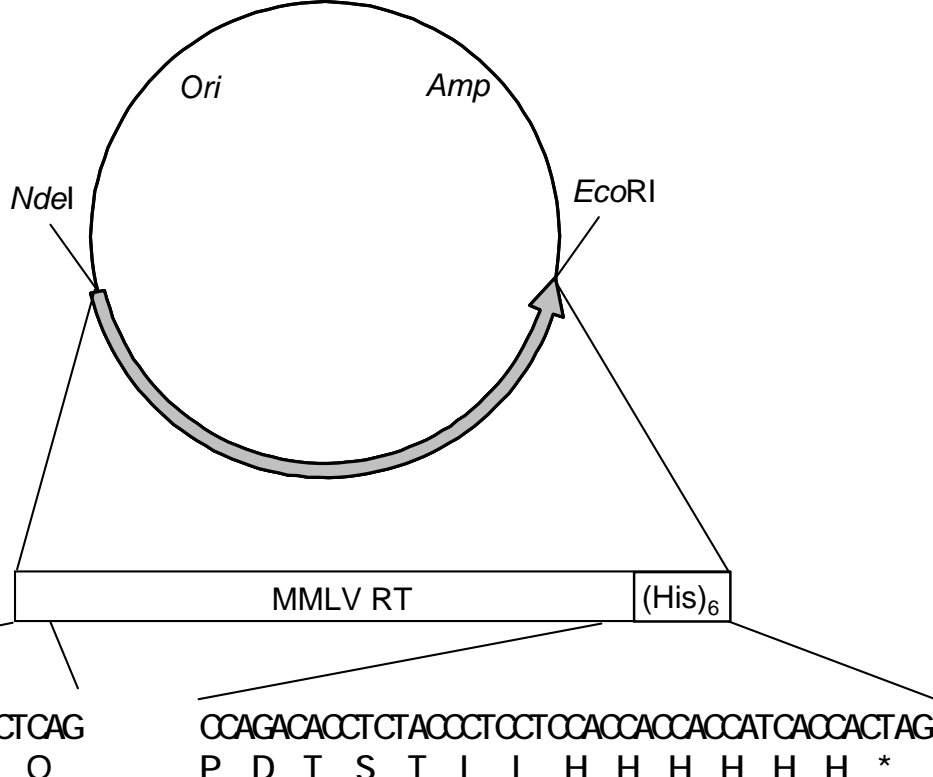

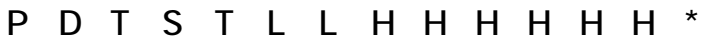

pET-HIVMp66
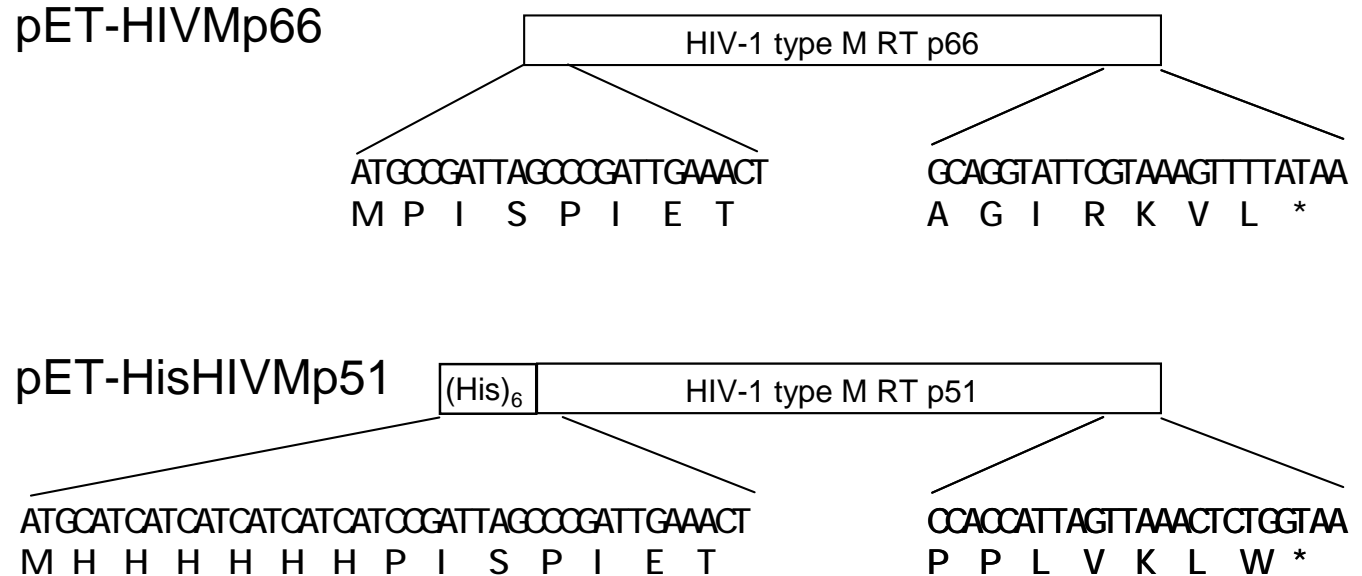

pET-HIVOp66
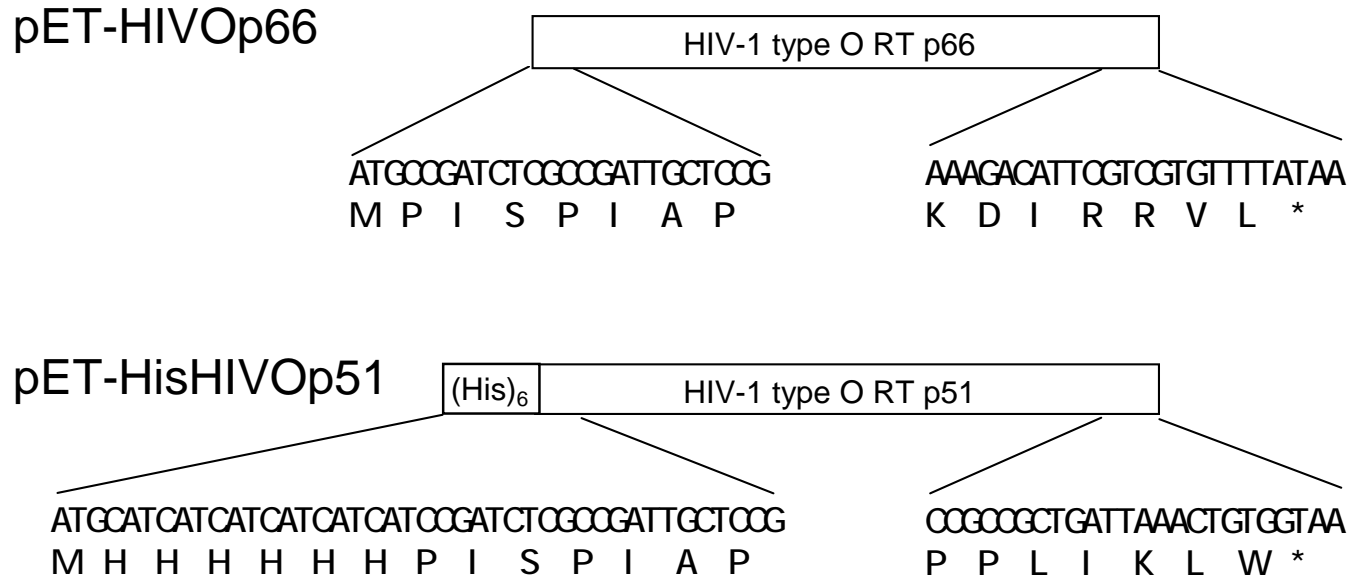

Fig. 1 
A

B

$\begin{array}{llllll}1 & 2 & 3 & 4 & 5 & 6\end{array}$

$\mathrm{kDa}$

$\mathrm{kDa}$

97.2

97.2

66.4

66.4

44.3

44.3

29.0

$\begin{array}{llllll}1 & 2 & 3 & 4 & 5 & 6\end{array}$

29.0

$\begin{array}{llllll}1 & 2 & 3 & 4 & 5 & 6\end{array}$

$\mathrm{kDa}$

97.2

66.4

44.3

29.0

Fig. 2 
A

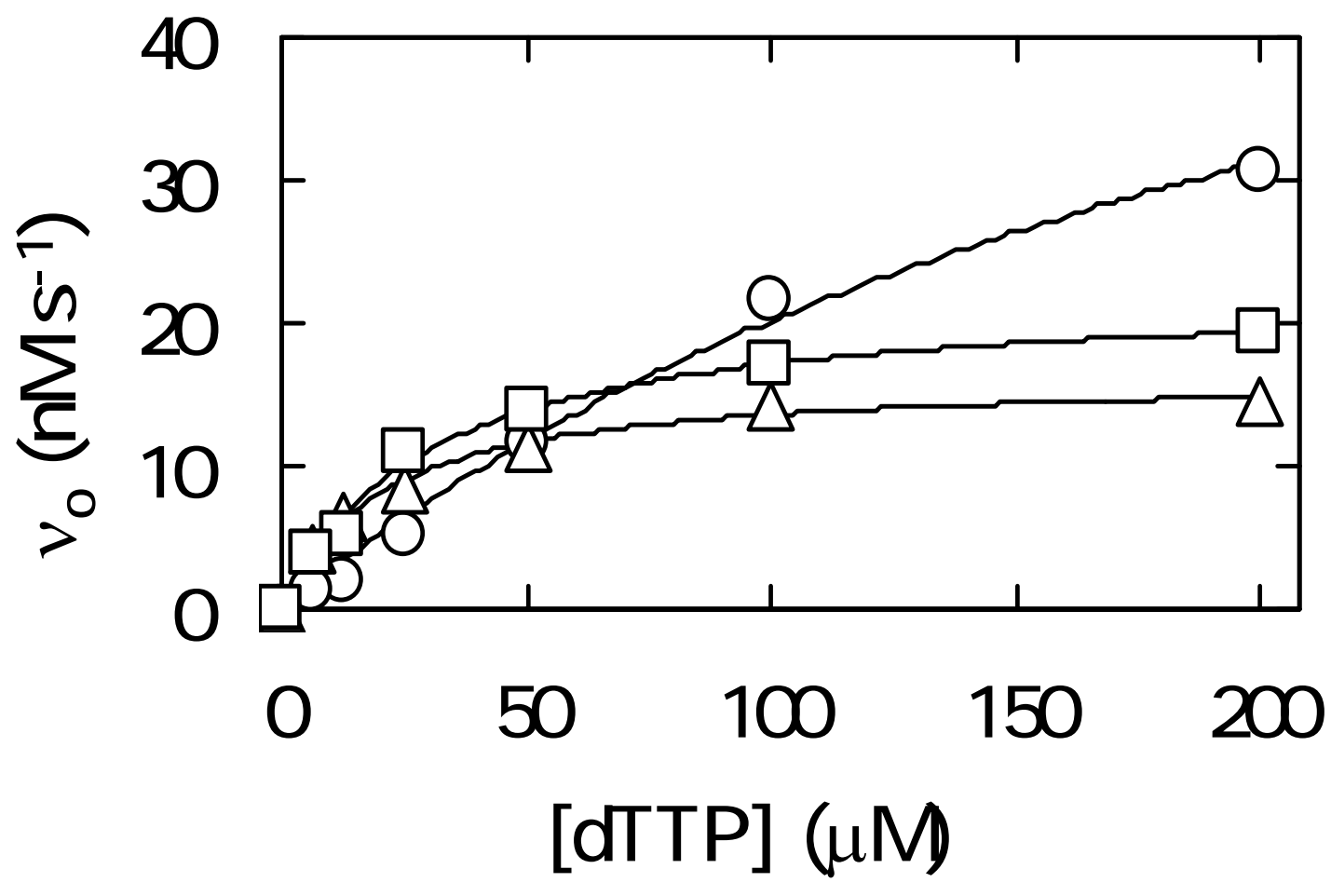

B

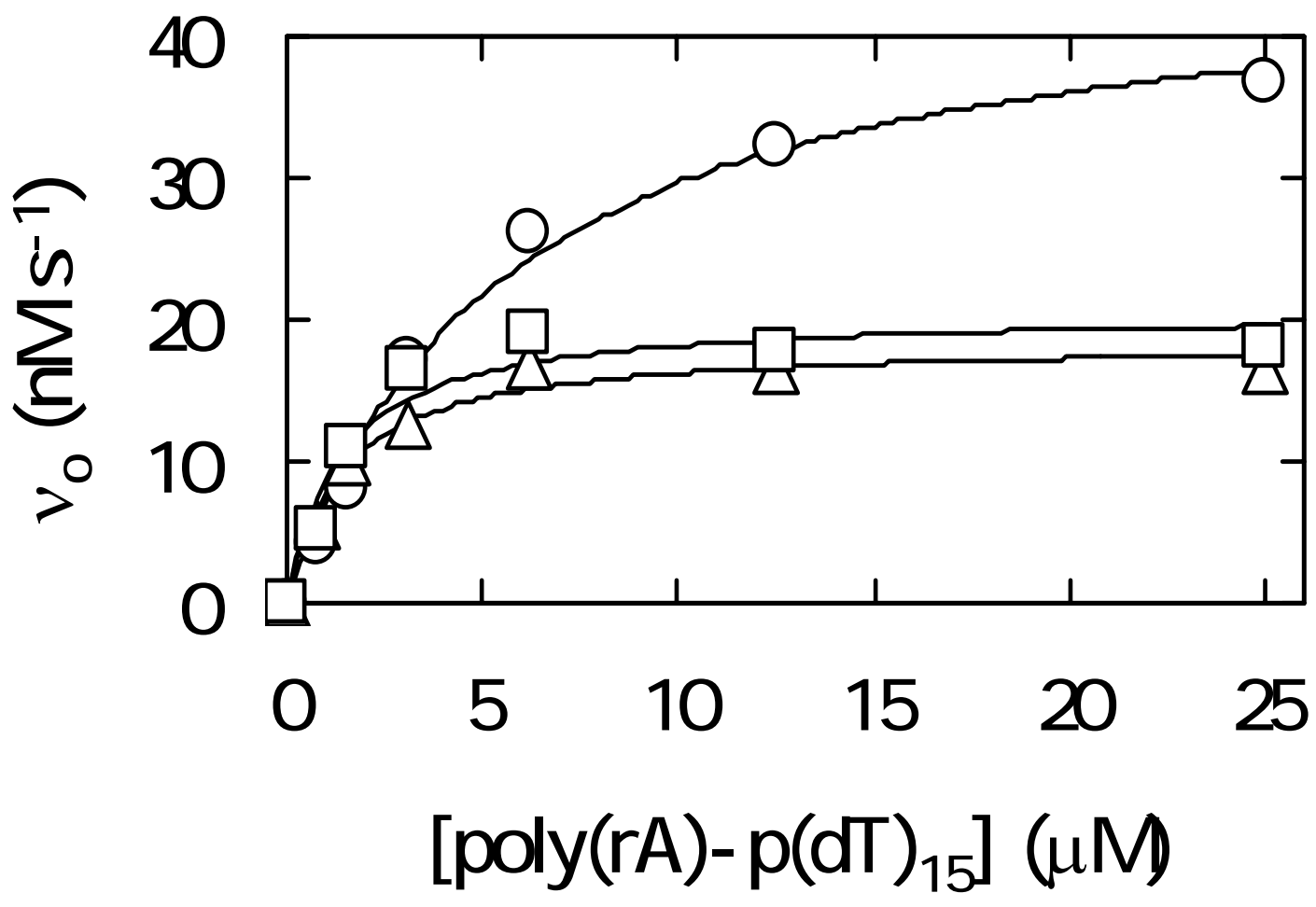

Fig. 3 
A

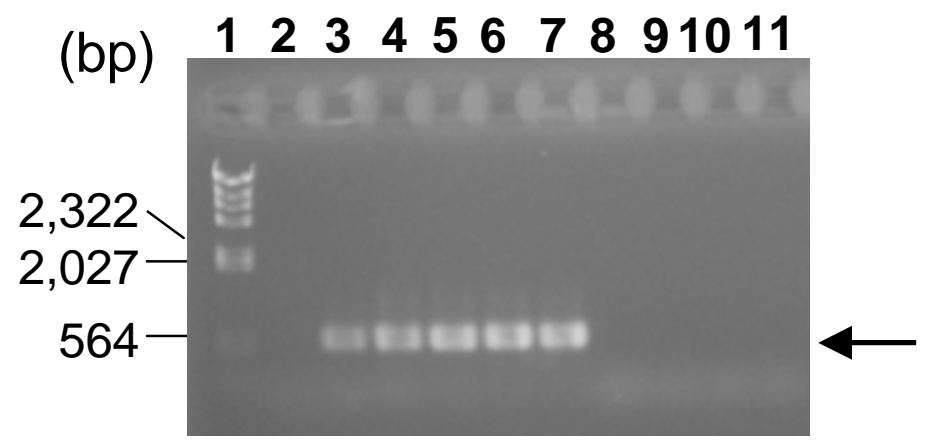

B

1234567891011

$\cos 2 \cos 2$

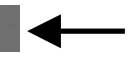

C

1234567891011

Fig. 4 
A

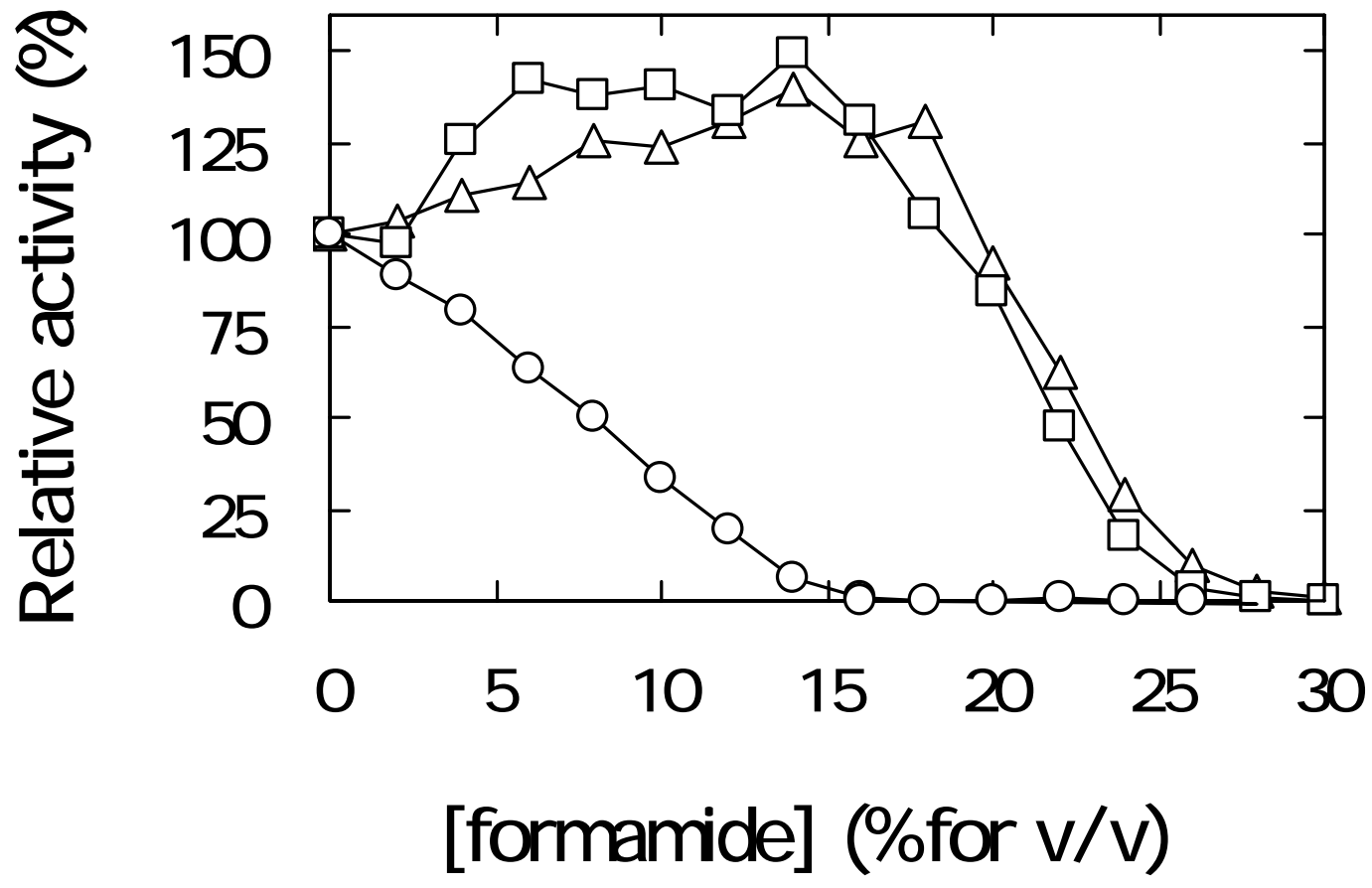

B

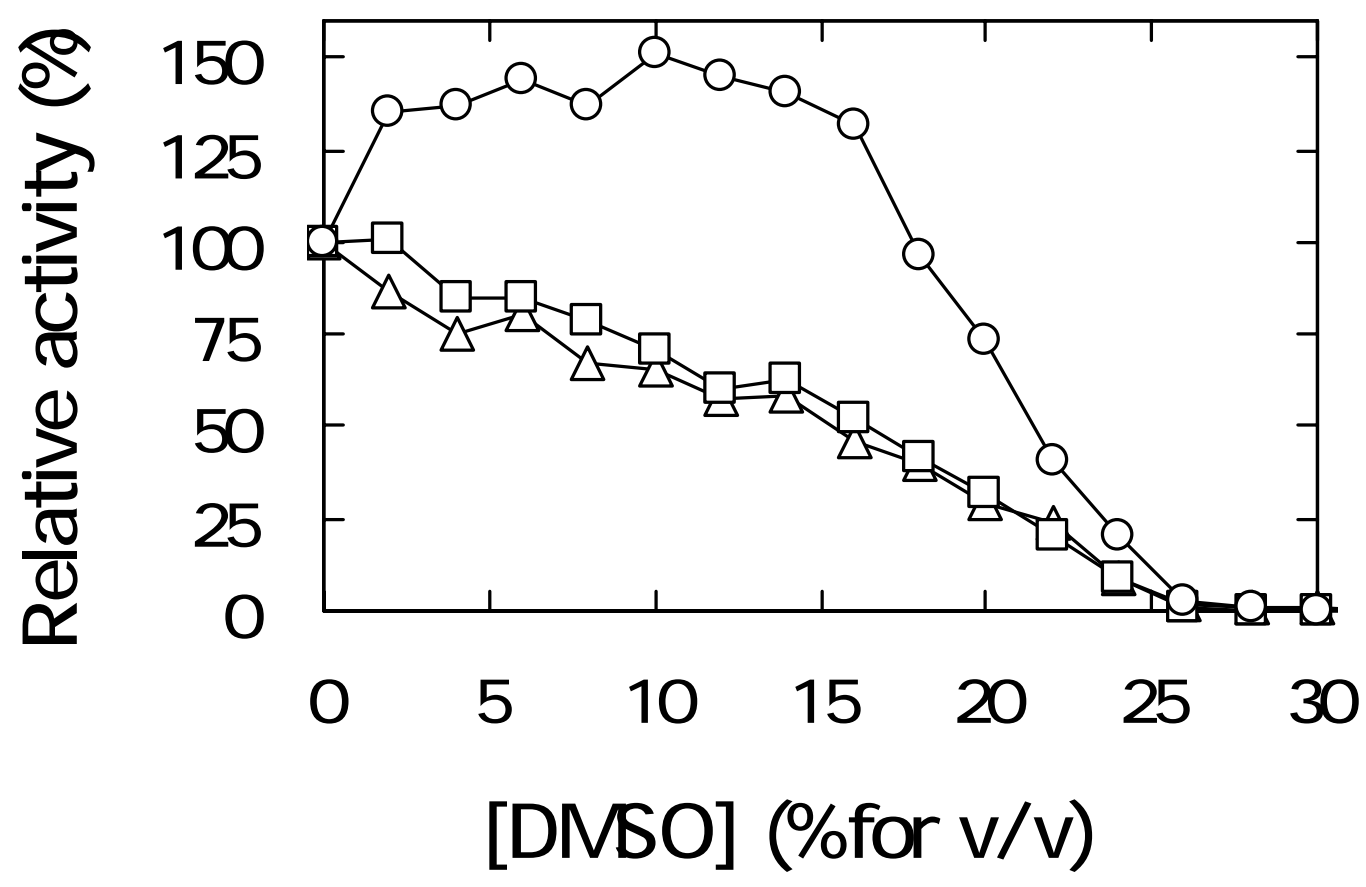

Fig. 5 


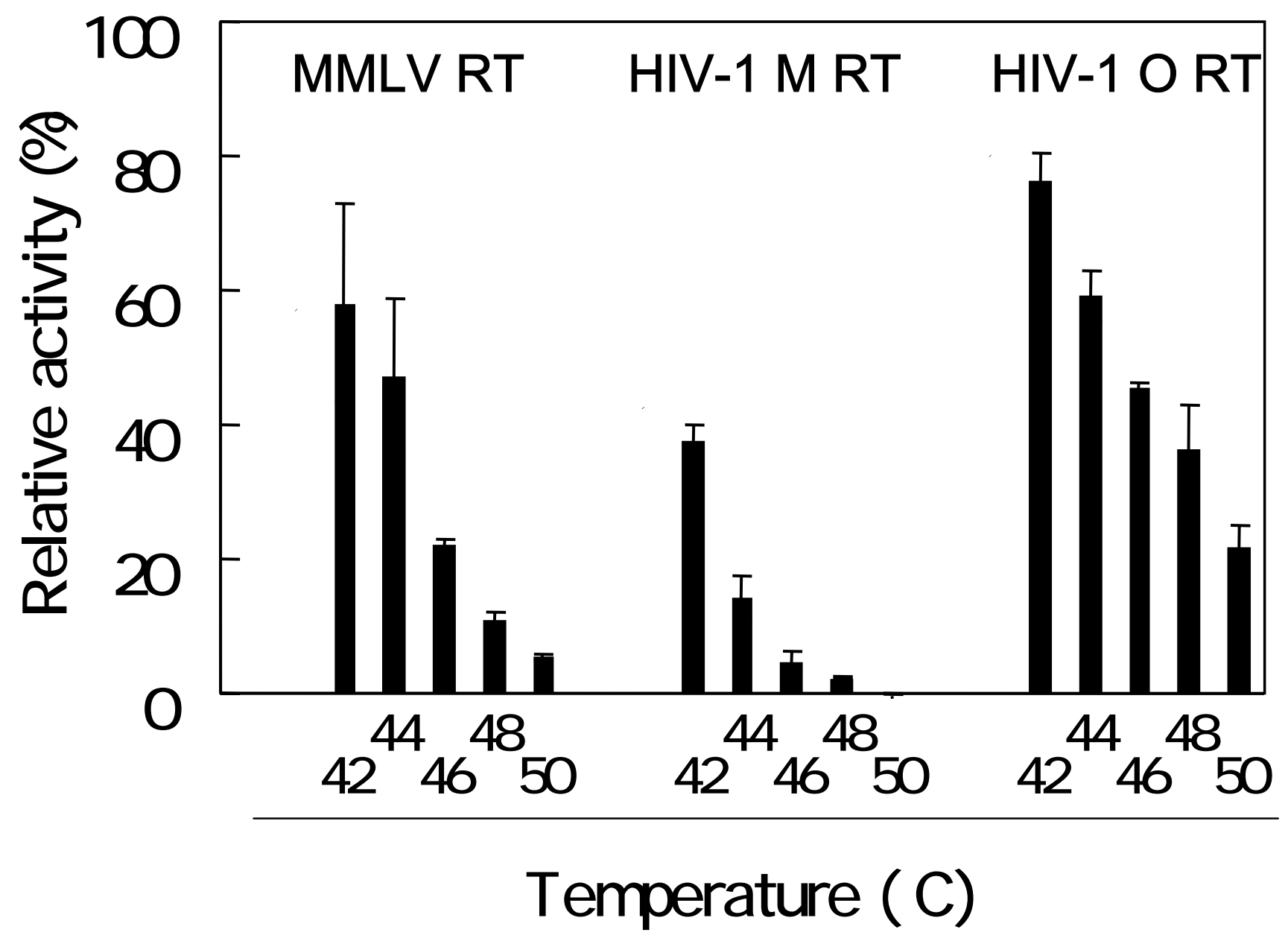

Fig. 6 


\section{Table 1}

Kinetic parameters of RT in the to incorporation of dTTP into poly(rA)-p(dT) 15 (T/P) at $37^{\circ} \mathrm{C}$.

\begin{tabular}{lcll}
\hline RT & $K_{\mathrm{m}, \mathrm{dTTP}}(\mu \mathrm{M})$ & $K_{\mathrm{m}, \mathrm{T} / \mathrm{P}}(\mu \mathrm{M})$ & $k_{\text {cat }}\left(\mathrm{s}^{-1}\right)$ \\
\hline MMLV RT & $250 \pm 60(1.0)$ & $5.6 \pm 0.8(1.0)$ & $29 \pm 6(1.0)$ \\
HIV-1 M RT & $20 \pm 2(0.080)$ & $1.4 \pm 0.2(0.25)$ & $0.35 \pm 0.02(0.012)$ \\
HIV-1 O RT & $30 \pm 4(0.12)$ & $1.3 \pm 0.4(0.23)$ & $1.1 \pm 0.1(0.038)$ \\
\hline
\end{tabular}

Average of triplicate determinations with SD value is shown. Numbers in parentheses indicate values relative to MMLV RT. 
91

31

181

61

271

91

361

121

451

151

541

181

601

201

721

241

811

271

901

301

991

331

1081

361

1171

391

1261

421

1351

451

1441

481

1531

511

1621

541

œGATTAGCCCGATTGAAACT GTGCOCGTTAAACT GAAACCAGGTATGGATGGAOCGAAAGTAAAACAATGGOCACTGACAGAAGAAAAG

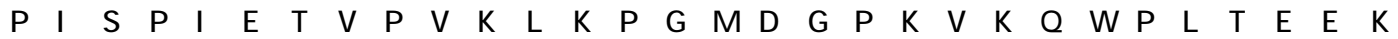
ATTAAAGCACT GGTTGAAATTTGCAOCGAATTGAAAAAGAAGGCAAAATCTCTAAAATTGGGCCOGAGAACOCGTATAACACOCCGCTG

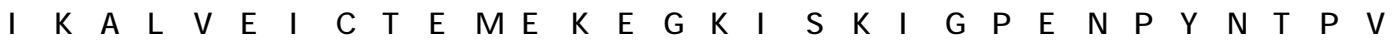
TTTGCAATTAAAAAAAAAGATTCTACAAAGTGGOGTAAATTGGTAGATTTCOGCGAGCTTAATAAACGCACTCAAGATTTCT GGGAAGT

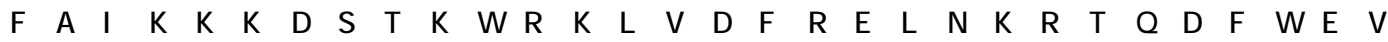
CAACTTGGGATTCCTCACOCCGOCGGTCTGAAAAAGAAAAAATCAGTGACTGTTTGGATGTAGGAGATGCATATTTTAGOGTOCCCTTG

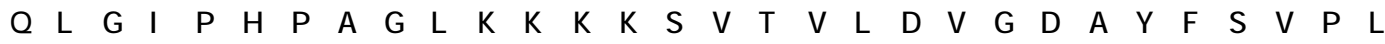
GATTTCGATTTTCGTAAATATAOCGCATTCACTATCOCGTCTATTAACAATGAAACACCAGGCATTCGTTACCAATATAACGTACTTOCT

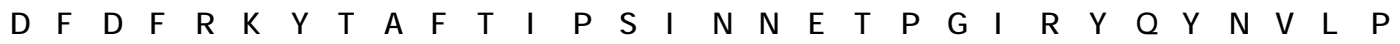
CAAGGTTGGAAAGGCT CTOCCGOCATTTTTCAGTCGAGTATGACTAAAATCTTGGAACCTTTOCGCAAACAAAATCOGGACATTGTTATC

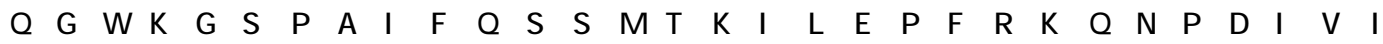
TACCAGT ACATGGATGATCT GT AT GTTGGATCCGACCT GGAAATCGGACAACATOGCACAAAAATOGAAGAGCT GCGT CAACAOCTTCTG

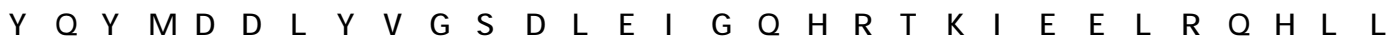
@GCT GGGGCTTGACTACAOCTGACAAAAAACATCAAAAAGAACCACCGTTCCTGTGGATGGGTTATGAATTGCACCCTGACAAATGGACC

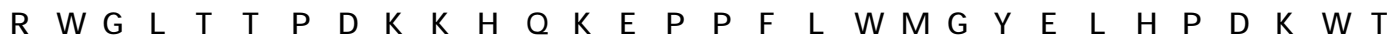
GTTCAACCTATOGTOCTGOCCGAAAAAGACAGCTGGACGGTTAATGACATTCAAAAGTTGGTAGGCAAGTTAAATTGGGCATCTCAGATT

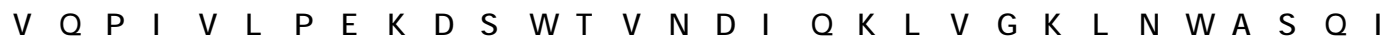
TACCOGGGCATTAAAGT GOGCCAACTTTGTAAACT GCT GCGCGGCACCAAGGCTCT GAOCGAAGTCATCOCTCTGAळCGAGAAGCT GAA

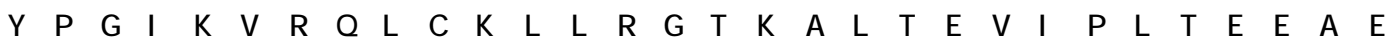
CT GGAACTTGCAGAGAACOGCGAAATTCTGAAAGAAOCCGTCCATGGAGTGTATTATGACCCAAGTAAAGATTTGATTGCOGAAATTCAA

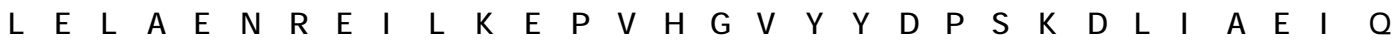
AAACAAGGACAAGGOCAATGGAOCTATCAGATTTATCAAGAACCTTTTAAAAACTTAAAAACTGGAAAATATGCACGCATGCGOGGT GCG

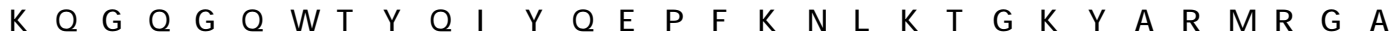
CATACAAACGATGTTAAACAGCTGACAGAAGCOGTACAAAAAATTACAACAGAATCCATTGTAATCTGGGGAAAAACACCGAAATTTAAA

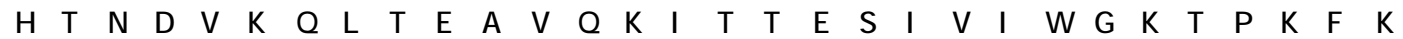
TTAOCGATTCAAAAAGAGACGT GGGAAACGT GGT GGACCGAATACT GGCAGGCAACCT GGATTCCGGAATGGGAATTTGTAAACACOCCA

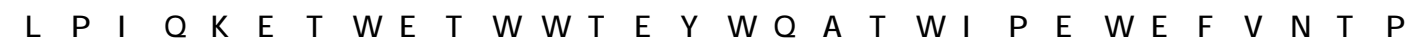
œATTAGTTAAACTCT GGTATCAACTCGAAAAAGAAœCGTTGTAGGGGCAGAAACTTTTTATGTGGACGGAGCTGOGAATCGOGAAACG

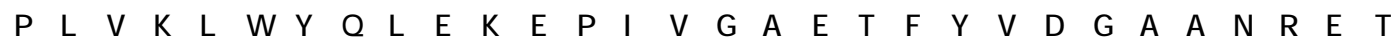
AAATTAGGTAAAGCTGGATATGTGAOGAATCGOGGGOGCCAAAAAGTAGTAACCCTCAOCGATACCACTAATCAAAAAACOGAACTOCAA

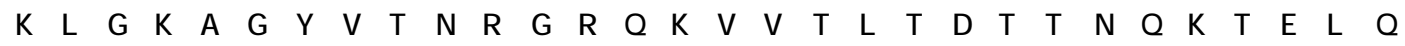
GCAATTTACCT@GCOCTGCAAGATTCAGGCTTAGAAGTTAACATTGTCACTGATAGCCAATACGCOCTTGGTATTATTCAAGCACAGCCG

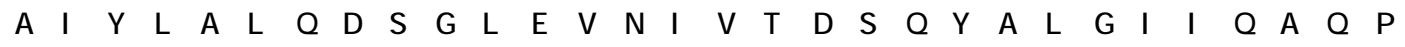
GATCAAAGCGAATCAGAATTAGTCAATCAGATTATTGAACAATTAATTAAAAAAGAGAAAGTATATTTAGCCTGGGTACCAGCOCATAAA

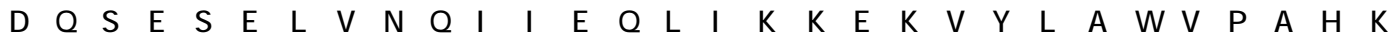
AAAGGAATTGGTGGCAACGAACAGGTAGACAAACTGGTATCT GCAGGTATTOGTAAAGTTTTATAA

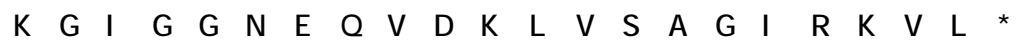

Fig. S1 Nucleotide sequences of artificially synthesized HIV- 1 M RT DNA. The amino acid sequences is also shown 
CCGATCTCGCOGATT GCTCCGGT GOCGGTGAAACT GAAAOCGGGT ATGGATGGTCCGAAAGT GAAACAAT GECCGCTGTCTCGT GAAAAA

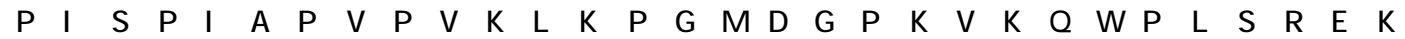
ATTGAAGCACTGAOCGCTATCTGCCAGGAAATGGAACAAGAAGGCAAAATTTCACGT ATCGGT COGGAAAA@CCGTATAATAOGCCGATT I $E$ E A L TTTGCCATTAAGAAAAAAGATTCGACCAAATGECGCAAACT GGT GGACTTTCGTGAACT GAACAAACGCACGCAGGATTTCTGGGAAGTT

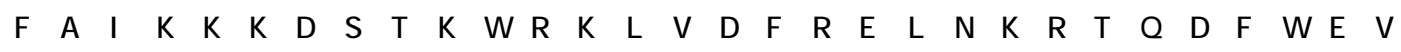

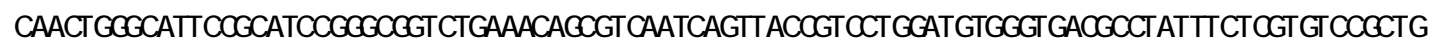

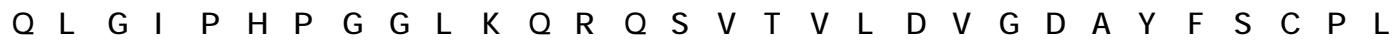
GATœGGACTTTCGT AAATACACCGCATTCACGATœCGAGCGITAACAATGAAACCOCGGGCGTGCGCTATCAGTACAACGTTCTGCCG

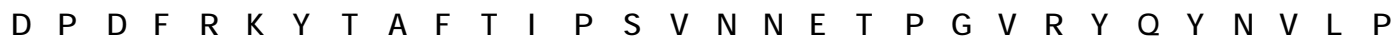
CAAGGCTGGAAAGGTTCTCCGQCTATTTTTCAGAGCTCTATGACCAAAAT@TGGAT@GTTCCGTAAAAGTAATळGGAAGTGGAAATT

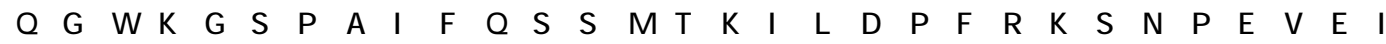
TATCAGTACATCGATGAOTGTATGTTGGTTCOGATCTGOCGCT GGCAGAACATCGT AAACGCGTGGAACT $@$ CT GOGCGAACACCTGT AC Y $Q \quad Y \quad I \quad D \quad D \quad L \quad Y \quad V \quad G \quad S \quad D \quad L \quad P \quad L \quad A \quad E \quad H \quad R \quad K \quad R \quad V \quad E \quad L \quad L \quad R \quad E \quad H \quad L \quad Y$ CAGTGGGGCTTTAœACGCCGGATAAAAAACATCAGAAAGAAœGCOGTTOCTGT GGATGGGTTATGAACT CCACOCGGACAAATGGACG

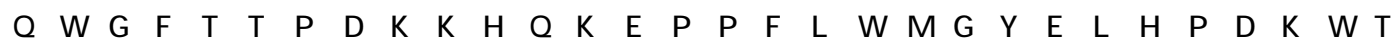
GTTCAGOCGATTCAACT GCCGGATAAAGAAGTGI GGACCGITAACGACATOCAGAAACT GGTCGCCAAACTGAATTGGGOCAGCCAGATT

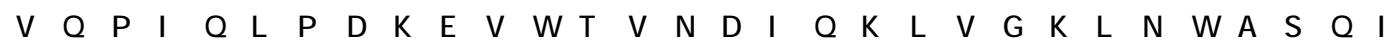
TACCAAGGT ATCCGT GT GAAAGAACT GT GCAAACT GATTOGCGGCACGAAAAGOCTGACCGAAGTGGTTCCGCTGTCTAAAGAAGCAGAA

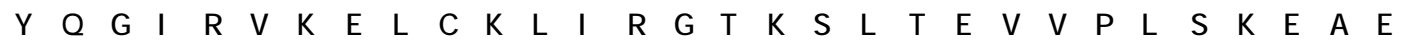
CTGGAACT GGAAGAAACCGCGAAAACTGAAAGAACCGGT CCATGGT GT GTATTACCAGCOGGATAAAGAOCTGTGGGTTAGCATTCAG $\begin{array}{llllllllllllllllllllllllllllll}L & E & L & E & E & N & R & E & K & L & K & E & P & V & H & G & V & Y & Y & Q & P & D & K & D & L & W & V & S & I & Q\end{array}$ AAACATGGCGAAGGT CAATGGACCTATCAGGTCTACCAAGATGAACACAAAAAœTGAAAA@GGGCAAATACGCGOGTCAGAAAGCCAGC $K \quad H \quad G \quad E \quad G \quad Q \quad W \quad T \quad Y \quad Q \quad V \quad Y \quad Q \quad D \quad E \quad H \quad K \quad N \quad L \quad K \quad T \quad G \quad K \quad Y \quad A \quad R \quad Q \quad K \quad A \quad S$ CACACCAATGACATCCGOCAGCT GCCT GAAGT OGT CCAGAAAGT CTCTCAAGAAGCGATTGTGATCTGGGGTAAACT GCOGAAATTTCGT $H$ T N D I R Q L A E V V Q K V S Q E A I V I W G K L P K F R CTGOCGGT GAOCCCGAAACGTGGGAAAœTTGGT GGGCCGAATATTGGCAGGCAACGTGGATTCOGGAATGGGAATTTGTTAGTACOCCG

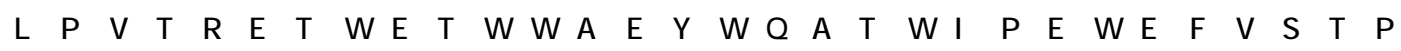
CCGCTGATTAAACTGT GGT ATCAGCT GGAAACGGAACCGATCGTTGGCGCTGAAACCTTCTACGTCGATGGTGCGGCCAACCGTAATACG $\begin{array}{lllllllllllllllllllllllllllllll}P & L & I & K & L & W & Y & Q & L & E & T & E & P & \text { I } & V & G & A & E & T & F & Y & V & D & G & A & A & N & R & N & T\end{array}$ AAACT GGGCAAAGOGGGTTATGT GACCGAACAGGGCAAACAAAACATTATCAAACTGGAAGAAAOCACGAATCAGAAAGCAGAACTGATG $\begin{array}{lllllllllllllllllllllllllllllll}K & L & G & K & A & G & Y & V & T & E & Q & G & K & Q & N & I & I & K & L & E & E & T & T & N & Q & K & A & E & L & M\end{array}$ GCTGTTCTGATTGOGCTGCAGGATAGTAAAGAACAAGTTAATATCGTCACGGACTCCCAGTACGTCCTGGGTATTATCAGTTळCAGCCG

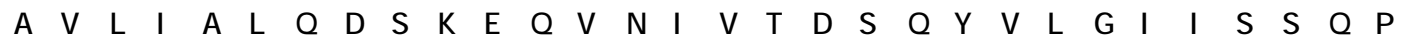
ACCCAATCAGATTCGCCGATTGTCCAGCAAATTATCGAAGAACTGACCAAAAAAGAACGCGT GT ATCTGACCTGGGTTCCGGCACACAAA

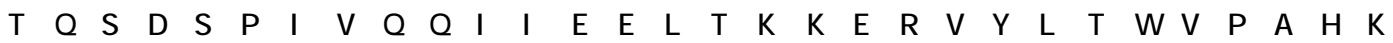
AAAGGCATCGGOGGTAACGAAAAATTGATAAACT GGTTTCTAAAGACATTOGTOGTGTTTTATAA

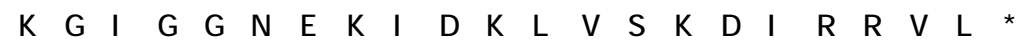

Fig. S2 Nucleotide sequences of artificially synthesized HIV- 1 M RT DNA. The amino acid sequences is also shown 


\section{Table S1}

Primers.

\begin{tabular}{|c|c|}
\hline Primers & Sequences $\left(5^{\prime}-3\right.$ ') \\
\hline MRF & 5'-AAGGAGATATACATATGACATGGCTGTCTG-3' \\
\hline MRHISB & $\begin{array}{l}\text { 5'-CTGAATTCTAGTGGTGATGGTGGTGGTGGAGGAGGG } \\
\text { TAGAGGTGTCT-3' }\end{array}$ \\
\hline HIVRTM-HISF & $\begin{array}{l}\text { 5'-CCTTTTCATATGCATCATCATCATCATCATCCGATTA } \\
\text { GCCCGATTGAAACTG-3' }\end{array}$ \\
\hline HIVRTMp51-B & 5'-TTTTCGAATTCTTACCAGAGTTTAACTAATGGTG-3' \\
\hline HIVRTM-F & 5'-CCTTTTCATATGCCGATTAGCCCGATTG-3' \\
\hline HIVRTMp66-B & 5'-TTTTGAATTCTTATAAAACTTTACGAATACC-3' \\
\hline HIVRTO-HISF & $\begin{array}{l}\text { 5'-CCTTTTCATATGCATCATCATCATCATCATCCGATC } \\
\text { TCGCCGATTGCTCCGG -3' }\end{array}$ \\
\hline HIVRTOp51-B & 5'-TTTTCGAATTCTTACCACAGTTTAATCAGCG-3' \\
\hline HIVRTO-F & 5'-CCTTTTCATATGCCGATCTCGCCGATTG-3' \\
\hline HIVRTOp66-B & $\begin{array}{l}\text { 5'-TTTTGAATTCTTATTATAAAACACGACGAATGTCT } \\
\text { TTAGAAACCAGTTTATCAATTTTTTCG-3' }\end{array}$ \\
\hline
\end{tabular}

The mismatched nucleotides with the sequence of the MMLV RT, HIV-1 M RT, or HIV-1 O RT gene are underlined. 
Table S2

Representative purification of RT.

\begin{tabular}{|c|c|c|c|c|c|c|}
\hline Stage & $\begin{array}{l}\text { Volume } \\
\text { (mL) }\end{array}$ & $\begin{array}{l}\text { Activity } \\
\left(\text { units }^{\mathrm{a}}\right)\end{array}$ & $\begin{array}{c}\text { Recovery } \\
(\%)\end{array}$ & $\begin{array}{l}\text { Protein } \\
(\mathrm{mg})\end{array}$ & $\begin{array}{l}\text { Specific activity } \\
\quad \text { (units/mg) }\end{array}$ & $\begin{array}{l}\text { Purification } \\
\text { (fold) }\end{array}$ \\
\hline \multicolumn{7}{|l|}{ i) MMLV RT } \\
\hline$\left(\mathrm{NH}_{4}\right)_{2} \mathrm{SO}_{4}$ fractionation & 6.0 & 928,000 & 100 & 21 & 44,000 & 1.0 \\
\hline DEAE Toyopearl & 16 & 553,000 & 60 & 13 & 43,000 & 1.0 \\
\hline $\mathrm{Ni}^{2+}$ Sepharose & 2.5 & 629,000 & 68 & 4.3 & 150,000 & 3.4 \\
\hline Purified enzyme & 0.7 & 372,000 & 40 & 2.0 & 190,000 & 4.3 \\
\hline \multicolumn{7}{|l|}{ ii) HIV-1 group M RT } \\
\hline$\left(\mathrm{NH}_{4}\right)_{2} \mathrm{SO}_{4}$ fractionation & 8.0 & 6,310 & 100 & 24 & 260 & 1.0 \\
\hline DEAE Toyopearl & 16 & 5,070 & 80 & 7.5 & 680 & 2.6 \\
\hline $\mathrm{Ni}^{2+}$ Sepharose & 2.5 & 2,080 & 33 & 1.3 & 1,500 & 5.8 \\
\hline Purified enzyme & 0.7 & 1,760 & 28 & 0.9 & 1,900 & 7.3 \\
\hline \multicolumn{7}{|l|}{ iii) HIV-1 group O RT } \\
\hline$\left(\mathrm{NH}_{4}\right)_{2} \mathrm{SO}_{4}$ fractionation & 12 & 16,800 & 100 & 52 & 320 & 1.0 \\
\hline DEAE Toyopearl & 28 & 20,400 & 120 & 21 & 970 & 3.0 \\
\hline $\mathrm{Ni}^{2+}$ Sepharose & 2.5 & 5,190 & 31 & 1.3 & 4,000 & 13 \\
\hline Purified enzyme & 0.7 & 3,910 & 23 & 0.8 & 5,000 & 16 \\
\hline
\end{tabular}

${ }^{\mathrm{a}}$ One unit of RT is defined as the amount which incorporates $1 \mathrm{nmol}$ of dTTP into $\operatorname{poly}(\mathrm{rA})-\mathrm{p}(\mathrm{dT})_{15}$ in $10 \mathrm{~min}$ at $37^{\circ} \mathrm{C}$. 